\title{
Projeto "Floresta-escola" - educaçÃo ambiental não formal COM INSTITUIÇÕES PÚBLICAS
}

\author{
The "Floresta-Escola" project - envinronmetal nonformal education \\ with public institutions
}

\section{Proyecto "Floresta-Escola"- educación medioambiental no formal con instituciones publicas}

\author{
Daniela Biondi ${ }^{1}$ \\ Antonio Carlos Batista²
}

\begin{abstract}
RESUMO
Este trabalho descreve as atividades do projeto de extensão Floresta-Escola, desenvolvido por acadêmicos do curso de engenharia florestal no Campus III da UFPR e em várias escolas públicas da cidade de Curitiba. O objetivo geral do projeto foi transmitir conhecimentos conservacionistas através da educação ambiental não formal tanto numa Floresta (remanescente florestal no campus III - Jardim Botânico-Curitiba-PR) como nas escolas públicas, através de visitas monitoradas dos estudantes das escolas à trilha da Floresta, planejamento e elaboração de atividades lúdicas, oficinas e palestras nas escolas pelos acadêmicos bolsistas do projeto e realização de pesquisas sobre os diversos componentes do ecossistema florestal encontrados ao longo da trilha para dar suporte às atividades de educação ambiental. Em 2010 foram atendidos 450 estudantes de 12 escolas para as atividades na trilha, foram realizadas 20 palestras em 14 escolas com 486 estudantes e 62 estudantes participaram das oficinas. Vinte acadêmicos do curso de engenharia florestal $e$ um acadêmico do curso de biologia participaram do projeto. Os resultados refletem a dimensão alcançada pelo projeto, concluindo-se que os objetivos foram alcançados: o projeto contribuiu significativamente para complementar a formação dos acadêmicos de engenharia florestal em educação ambiental e promoveu uma conscientização pela educação ambiental não formal para diversas escolas municipais de Curitiba. Palauras-chave: conservação da natureza; trilha; consciência ambiental.
\end{abstract}

\begin{abstract}
This paper describes the activities of the extension project "Floresta-Escola", developed by students of forestry, at the Campus III of Universidade Federal do Paraná and at various public schools in the city of Curitiba. The project's overall objective was to transmit knowledge conservation through not formal environmental education both in a Forest (forest remnant in campus III - Jardim Botânico-Curitiba-PR) as public schools, through monitored visits of students of schools to track the Forest, planning and development of recreational activities, workshops and lectures in schools by students and scholars of design research on the various components of the forest ecosystem found along the trail to support environmental education activities. In 2010450 students from 12 schools were attending for activities on the trail, there were 20 lectures in 14 schools with 486 students and 62 students participated in the workshops. Twenty students of forestry and one student of biology course participated in the project in 2010, developing the proposed activities. The results reflect the scale achieved by the project and may be concluded that the objectives were achieved: the project contributed significantly to supplement the training of forestry engineering students and promoted the environmental education by an awareness of non-formal environmental education for several schools
\end{abstract}

1 Engenheira Florestal, Dra., Professora Associada do Curso de Engenharia Florestal da UFPR

2 Engenheiro Florestal, Dr., Professor Associado do Curso de Engenharia Florestal da UFPR. 
in Curitiba. With this, the project contributed to the formation of future citizens who will preach respect for the environment.

Keywords: nature conservation; trail; environmental awareness.

\section{RESUMEN}

En este trabajo se describen las actividades del proyecto de extensión "Floresta-Escola", desarrollado por estudiantes de Ingeniería Forestal de la Universidade Federal do Paraná PR en el Campus III y en varias escuelas públicas de la ciudad de Curitiba. El objetivo general del proyecto fue transmitir conocimientos conservacionistas mediante la educación ambiental no formal tanto en un bosque (remanente de bosque en el campus III - Jardín Botánico-Curitiba-PR) como en las escuelas públicas, a través de las visitas monitoreadas de los estudiantes a las trillas del bosque, la planificación y el desarrollo de actividades recreativas, talleres y conferencias en las escuelas por los estudiantes becarios del proyecto y investigación de los distintos componentes del ecosistema forestal que se encuentran a lo largo de la trilla del bosque para apoyar las actividades de educación ambiental. En el año 2010450 estudiantes de 12 escuelas fueron atendidos en visitas a la trilla, hubo 20 conferencias en 14 escuelas con 486 alumnos y 62 alumnos participaron en los talleres. Veinte estudiantes de ingeniería forestal y uno del curso de biología participaron del proyecto. Los resultados reflejan la escala lograda por el proyecto y se concluye que los objetivos se lograron: el proyecto contribuyó significativamente a complementar la formación de estudiantes de ingeniería forestal en el tema de educación ambiental y se incentivó una concienciación por la educación ambiental non-formal para varias escuelas municipales de Curitiba. Además, el proyecto contribuyó para la formación de futuros ciudadanos que van preconizar el respecto por el medio ambiente.

Palabras-clave: conservación de la naturaleza; trilla; conciencia ambiental.

\section{Introdução}

A educação é a base para a conscientização de um individuo ou grupo social, permi- tindo estabelecer, através de seus julgamentos morais, uma harmonia entre os homens e entre o homem e a natureza. Visto que não se sabe tudo sobre a natureza do homem e nem a natureza da natureza, a relação homem-natureza deve ser um processo de contínuo respeito e aprendizado (BIONDI, 2008).

De acordo com Dias (2004), desde sua origem, o conceito de "meio ambiente" tem sido utilizado como sinônimo de "Natureza" ou "recursos naturais". Ainda hoje permanece forte a influência do pensamento conservacionista, o qual a "Natureza" deve ser reverenciada $e$ isolada do homem para ser salva. No entanto, reduzir esse conceito a aspectos exclusivamente "naturais" exclui as interdependências e interações com a sociedade. O meio ambiente, ou simplesmente ambiente, não é formado apenas pela flora e fauna, água, solo $e$ ar, como era tradicionalmente definido. O referido autor salienta: "Hoje, as atividades humanas sobre a Terra produzem tantas influências que a sua cultura passou a fazer parte da definição de meio ambiente" (DIAS, 2004).

A educação ambiental é uma ação interdisciplinar para ser trabalhada por todas as idades, comunidades e realidades, considerando o meio ambiente em sua totalidade: o resgate e o surgimento de novos valores sociais que conduzam a um modo de vida mais consciente e sustentável. Essa educação deveria preparar o indivíduo, mediante a compreensão dos principais problemas do mundo contemporâneo, proporcionando-lhe conhecimentos técnicos e as qualidades necessárias para desempenhar uma função produtiva, com vistas a melhorar a qualidade de vida e proteger o meio ambiente, prestando a devida atenção aos valores éticos (MACIEL et al., 2011).

Entende-se por educação ambiental não formal as propostas educativas que, sem ser curriculares, estão integradas em projetos com finalidades particulares e uma intencionalidade. A sua maior vantagem é que pode se desenvolver 
processos muito mais flexíveis do que no ensino formal, utiliza meios pedagógicos multivariados e tem a função de informar e formar (ARAUJO, 2006)

Articular a educação, em seu sentido mais amplo, com os processos de formação dos indivíduos como cidadãos, ou articular a escola com a comunidade educativa de um território é um sonho, uma utopia, mas também uma urgência e uma demanda da sociedade atual (GOHN, 2006).

Este projeto teve seu início com outro projeto de extensão intitulado Trilha da Floresta que teve como objetivo realizar atividades de educação ambiental, demonstrando a interdependência do homem com o meio que o envolve, conscientizando a sociedade da importância da utilização reflexiva e prudente dos recursos que atendem às necessidades humanas. Em 2009, com a ocorrência da suspensão dos ônibus que transportam as crianças por causa da gripe A e com a incidência da grande quantidade de chuvas, buscaram-se novas alternativas para os acadêmicos do curso de engenharia florestal desenvolverem atividades de educação ambiental com as crianças de escolas públicas. Devido a isto, procurou-se parceria junto a Secretaria Municipal de Defesa Social - Programa Guarda Mirim, para viabilizar a realização de atividades de educação ambiental nas escolas em forma de palestras e exposição de produtos florestais. Esta parceria veio preencher uma lacuna do referido programa em relação aos conhecimentos da conservação da natureza. E ao mesmo tempo proporcionou uma oportunidade para os acadêmicos desenvolverem atividades educativas e extensionistas, carente nos currículos acadêmicos de engenharia florestal.

O título desta pesquisa "Floresta-Escola" sugere que: a Floresta é uma escola - quando os acadêmicos recebem o público para as práticas educativas; e a Floresta vai à escola - quando os acadêmicos vão às escolas para transmitirem os conhecimentos relacionados com a floresta.
Na perspectiva acadêmica e social, a existência deste projeto justifica-se pelas seguintes razões:

a. A utilização da Floresta, remanescente florestal no campus III - Jardim Botânico, tanto para os aspectos científicos (pesquisas) como para os aspectos sociais (prática de educação ambiental) que, consequentemente, obriga a instituição (UFPR) estabelecer uma permanente manutenção e proteção da área;

b. Devido a falta de disciplinas ou estágios na área de extensão, as excursões guiadas que são realizadas criam oportunidades únicas para os acadêmicos complementarem as lacunas curriculares;

c. A transmissão de conhecimentos ecológicos e filosofias conservacionistas para as crianças de escolas públicas ajudam a formar cidadãos responsáveis pela natureza;

d. O contato dos acadêmicos com o público externo, através das palestras nas escolas, é um bom treinamento para uma boa oratória, desenvoltura, autoconfiança, expansividade e responsabilidade;

e. Com a formação das oficinas, tanto o público visitante como os acadêmicos terão oportunidade de desenvolver uma consciência ecológica, fazendo uso da criatividade através das diferentes práticas realizadas com materiais encontrados na floresta.

Tendo em vista o exposto anteriormente, o objetivo deste trabalho foi transmitir conhecimentos conservacionistas através da educação ambiental tanto numa Floresta (remanescente florestal no campus III - Jardim Botânico) como nas escolas públicas, através dos seguintes objetivos específicos:

a. Monitorar estudantes de escolas do Ensino Básico e Fundamental da Rede Pública e Privada, durante uma excursão à trilha numa área com Floresta localizada no campus III - Jardim Botânico, realizando atividades de educação ambiental com as crianças; 
b. Elaborar, desenvolver e exercitar atividades de educação ambiental junto aos monitores do projeto (estudantes bolsistas e voluntários) a fim de habilitá-los para o atendimento do público externo (escolas);

c. Ampliar o conhecimento dos estudantes do projeto sobre o remanescente de Floresta da trilha através da pesquisa, para servir de conteúdo às atividades desenvolvidas com as escolas visitantes e visitadas;

d. Estimular os acadêmicos a usarem mais a criatividade na forma de transmitir os conhecimentos ecológicos e filosofias conservacionistas para as crianças (elaboração de dinâmicas);

e. Planejar, elaborar e executar práticas educativas com produtos da floresta através de oficinas e palestras.

\section{Material e métodos}

Este projeto de extensão tem como público alvo estudantes do ensino básico, fundamental e médio de Escolas da Rede Pública e Privada de Ensino. Parte do projeto foi realizado na UFPR e outra parte foi realizada em várias escolas públicas.

O projeto possui parceria com a Secretaria Municipal de Defesa Social - Departamento de Promoção da Defesa Comunitária com o Programa Guarda Mirim que é responsável pela maioria da demanda das escolas agendadas. Além desta, tem como parceria, desde a origem do projeto, o PET-Floresta.

A metodologia deste projeto foi dividida em três atividades distintas: Excursão das escolas na trilha chamada "Trilha da Floresta" UFPR, Palestras nas Escolas - Floresta na Escola e Oficinas da Floresta.

\section{Excursão das escolas na trilha da Floresta-UFPR}

A excursão com as escolas conta com a seguinte infraestrutura: Centro de Educação Ambiental e um fragmento de floresta (Floresta Ombrófila Mista) bem conservado com área de 15 ha localizado no Campus Jardim Botânico - UFPR, onde foi construída uma trilha interpretativa com um percurso de $750 \mathrm{~m}$, sinalizada com placas para atividades educativas (Figura 1).

O Centro de Educação Ambiental é uma construção em madeira de pinus proveniente de reflorestamento, com uma área aproximada de $110 \mathrm{~m}^{2}$, que foi construída pela MOBASA - Battistella Indústria e Comércio Ltda. Neste local é realizada a recepção aos visitantes, além de dinâmicas que visam a integração do grupo e a sua preparação para o início das atividades na Trilha da Floresta. O Centro desempenha, ainda, a função de museu, com a exposição de diversos produtos da floresta e possui área para atividades em dias de chuva, quando não é possível percorrer o percurso da Trilha da Floresta.

A excursão das escolas à Trilha da Floresta é dividida em três fases:

Recepção-acontece com a chegada das crianças ao Centro de Visitação, onde todos se apresentam e participam das primeiras atividades lúdicas. Em seguida são levadas para o interior do Centro de Visitação onde observarão e terão informações sobre exsicatas de plantas, sementes, frutos, insetário, mapas e outros materiais referentes ao que será visto durante a caminhada na trilha. Em seguida a turma de estudantes é dividida em dois grupos que entram separadamente, cada grupo devendo ser acompanhado de pelo menos dois monitores do projeto;

Trilha - ao longo da trilha, são abordados conteúdos que fazem referência à interdependência do homem e do meio ambiente, conscientizando as crianças sobre a importância de uma utilização sustentável dos recursos naturais presentes na floresta. Além disso, é repassado, com muita propriedade, o máximo de informações sobre as espécies ali presentes na borda da trilha, tais como: nome po- 
pular, nome científico, familia, qual o seu papel na floresta, usos desta espécie, curiosidades e outros;

Encerramento - ao final da caminhada na trilha, os participantes voltam para o Centro de Visitação, onde têm um tempo livre para realizar brincadeiras e merendar. As atividades são encerradas com uma dinâmica de grupo para relembrar os principais pontos discutidos e o que elas aprenderam ao longo das atividades. Ao terminar todas as atividades, os estudantes recebem dos monitores um certificado prometendo serem defensores da natureza.

As atividades de educação ambiental realizadas durante a excursão na trilha são desenvolvidas de maneira não formal, tentando sempre associar os temas pertencentes às disciplinas da grade curricular das escolas. Busca-se sempre transmitir as informações ao ar livre, em contato com natureza.

A interpretação da natureza na Trilha da Floresta foi desenvolvida com as seguintes abordagens:

Água - onde se procura transmitir a importância da água para o homem, demonstrando a necessidade e os meios para a sua conservação, além da inter-relação da mesma com os demais elementos da floresta;

Solo - é enfatizada e demonstrada a interdependência floresta/solo;

Flora - a diversidade de espécies vegetais, a estruturação da floresta, bem como a relação existente entre as espécies é o maior enfoque dado;

Fauna - é demonstrado o papel da fauna para a manutenção da floresta, sensibilizando os visitantes sobre a relevância de sua conservação.

Para melhor aprendizado e sensibilização das crianças, os monitores sempre informam os conhecimentos dos componentes presentes na floresta para evitar uma abordagem teórica.

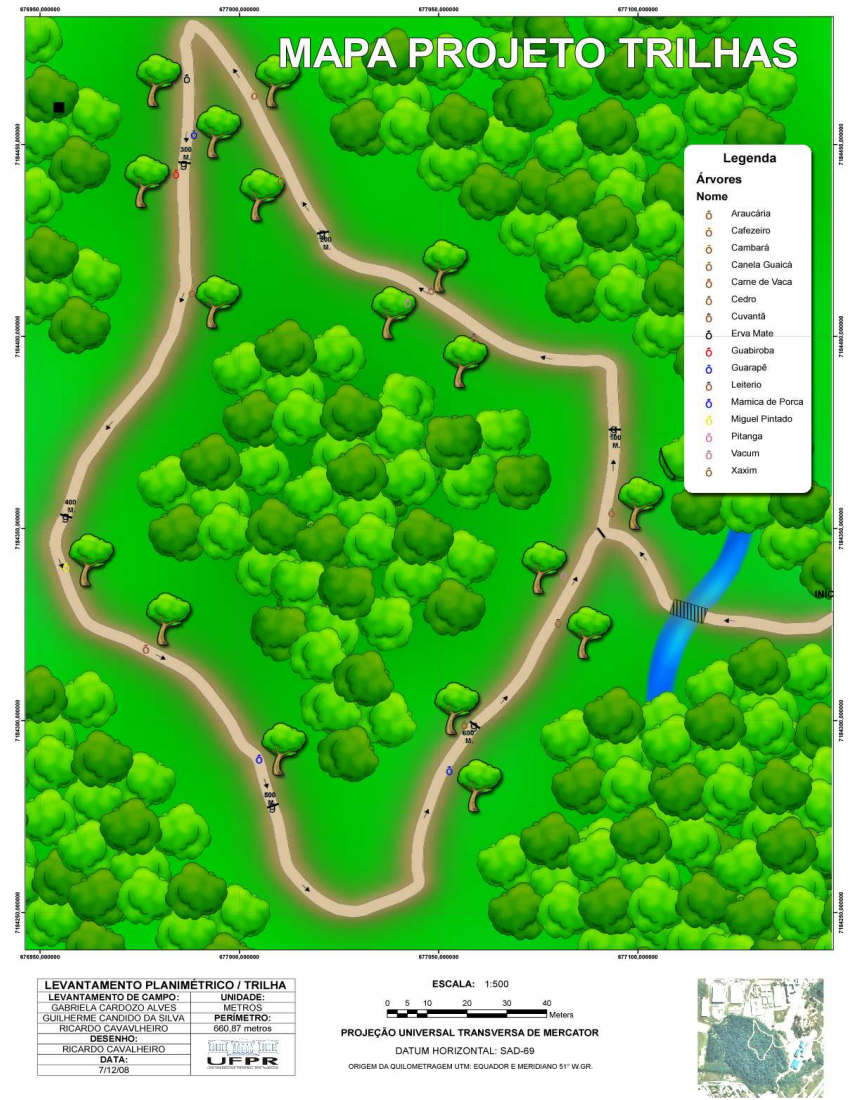

FIGURA 1 - PERCURSO DA TRILHA DA FLORESTA

\section{Palestras nas Escolas - Floresta na Escola}

As palestras nas escolas são realizadas pelos acadêmicos com apoio do Programa Guarda Mirim (agendamento das escolas e transporte). O tema principal das palestras é sempre relativo à conservação da natureza e principalmente das florestas. Desde que foi feita a parceria com o Programa Guarda Mirim, o tema da palestra é incrementado com a campanha anual deste programa. Neste ano de 2010 foi introduzida a abordagem sobre Responsabilidade Fiscal no tema Conservação da Natureza. Uma exposição de produtos da floresta (madeira, sementes, frutos, fibra de papel, remédios etc.) faz parte da finalização de cada palestra proferida nas escolas. 
Oficinas da Floresta

A realização das oficinas teve por objetivos: contribuir para a fixação dos conhecimentos conservacionistas adquiridos na excursão ou nas palestras; desenvolver a criatividade dos acadêmicos e dos estudantes das escolas; e promover também uma atividade recreativa. Os acadêmicos devem pesquisar temas que possam ser transformados em oficinas, tais como:

a. Oficina da Paisagem - ensinar os estudantes a criar paisagem numa cartolina com o uso de restos de folhas, galhos, cascas de frutos, sementes, pedra etc.;

b. Oficina do Barulho - ensinar os estudantes a fazer instrumentos que produzam sons com restos de bambu.

Todas as oficinas têm como introdução uma ligeira visita à floresta $e$ uma apresentação teórica sobre a metodologia do que será realizado na oficina.

A avaliação do projeto é feita de forma quantitativa, considerando o número de participantes do projeto, e qualitativa, através da análise das fichas de visitantes, que são preenchidas pelos bolsistas, contendo os dados dos perfis dos grupos de visitantes, como: faixa etária, procedência, nome da instituição, informações de conhecimento do projeto etc.

As observações dos bolsistas de extensão e voluntários também servem como avaliação, sendo discutidas em reuniões após cada atividade, auxiliando os acadêmicos envolvidos nos seus processos de formação, expressando opiniões e promovendo discussões acerca dos trabalhos realizados. Esses resultados são anotados nas fichas dos grupos de visitantes (avaliação contínua e participativa).

Após todas as atividades educativas (trilha, palestras e oficinas), descritas na metodologia deste projeto, é feita uma enquete com o público e os monitores do projeto para que as falhas sejam imediatamente corrigidas durante o desenvolvimento do mesmo (avaliação não cumulativa).

\section{Resultados e discussão}

Em 2010 foram atendidos 450 estudantes de 12 escolas para as atividades na trilha (Figura 2).
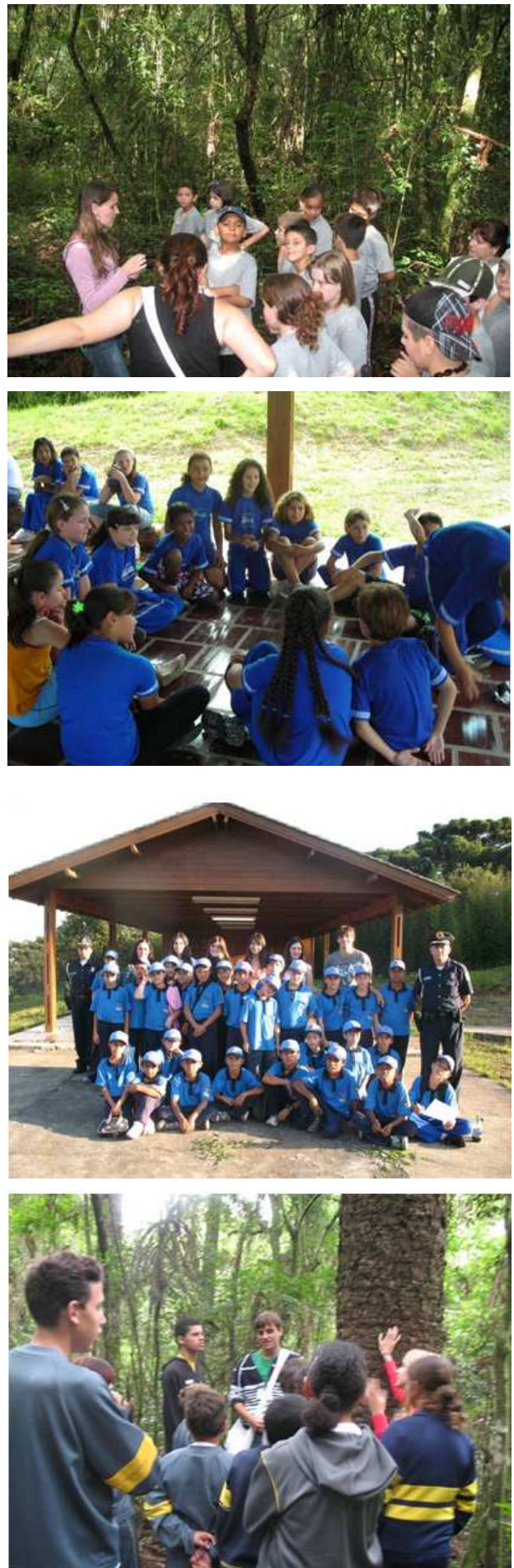

FIGURA 2 - ATIVIDADES DOS ESTUDANTES NA TRILHA DA FLORESTA 
Foram realizadas 20 palestras em 14 escolas com 486 estudantes (Figura 3) e 62 estudantes participaram das oficinas (Figura 4). Algumas escolas participaram mais de uma vez das atividades demonstrando que o projeto vem desempenhando um papel muito importante na complementação da educação formal.
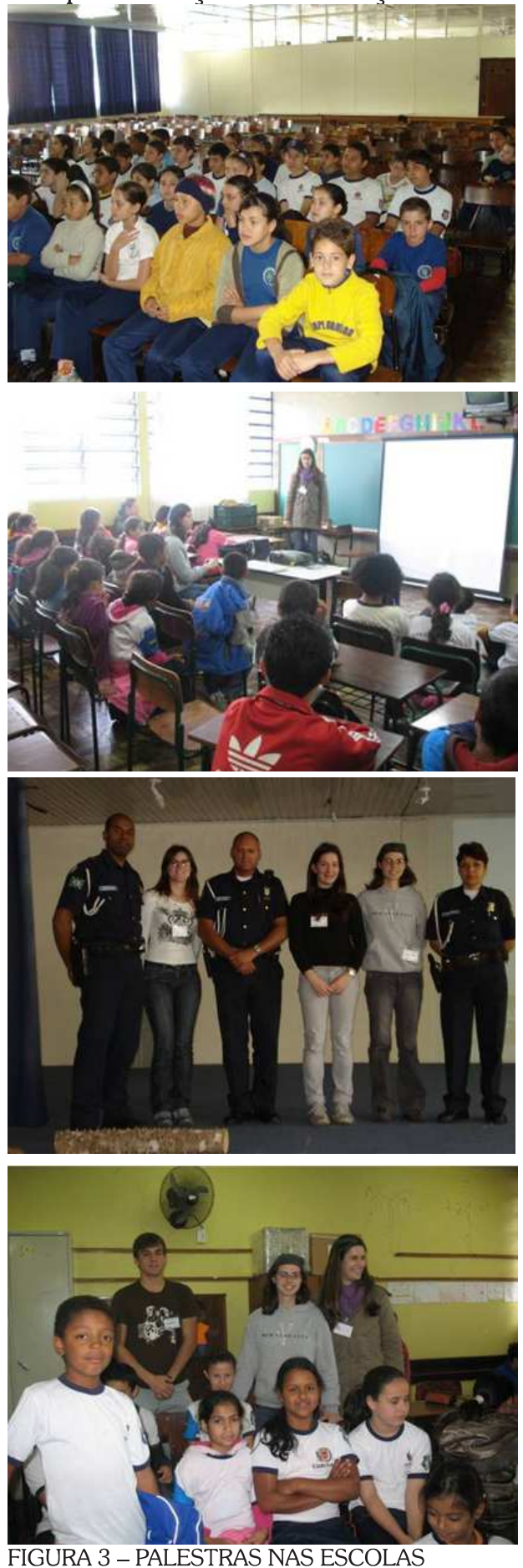

FIGURA 3 - PALESTRAS NAS ESCOLAS
Da avaliação feita pelos professores que acompanharam os estudantes das escolas visitantes, os resultados mais significativos foram: $100 \%$ responderam que as atividades do projeto Floresta-Escola corresponderam às expectativas; 95\% responderam que o tempo despendido para visita foi suficiente; $90 \%$ disseram que o atendimento pelos monitores foi ótimo; $24 \%$ sugeriram algumas melhorias no espaço físico que é anexo à trilha (Centro de Educação Ambiental); $29 \%$ afirmaram que a participação dos alunos no projeto serviu para fundamentar as aulas teóricas dadas em sala de aula; e $81 \%$ deram nota 10 ao projeto.

Além disso, as professoras afirmaram que o tema "preservação da natureza" presente no conteúdo abordado nas atividades é bastante interessante para as crianças, $e$ as atividades educativas e lúdicas desenvolvidas são adequadas às idades e séries escolares das crianças.
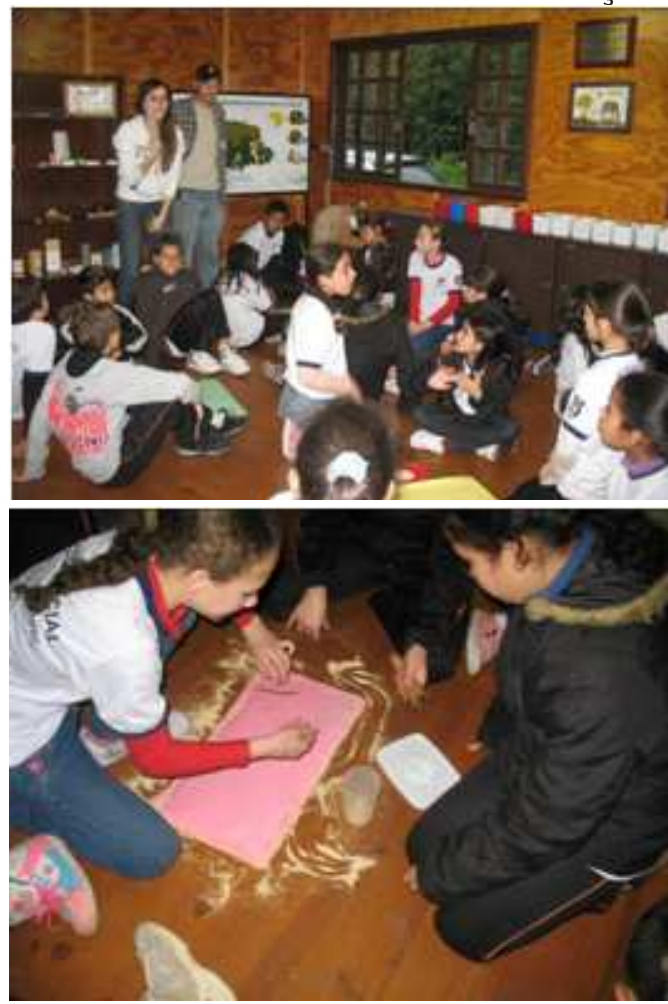


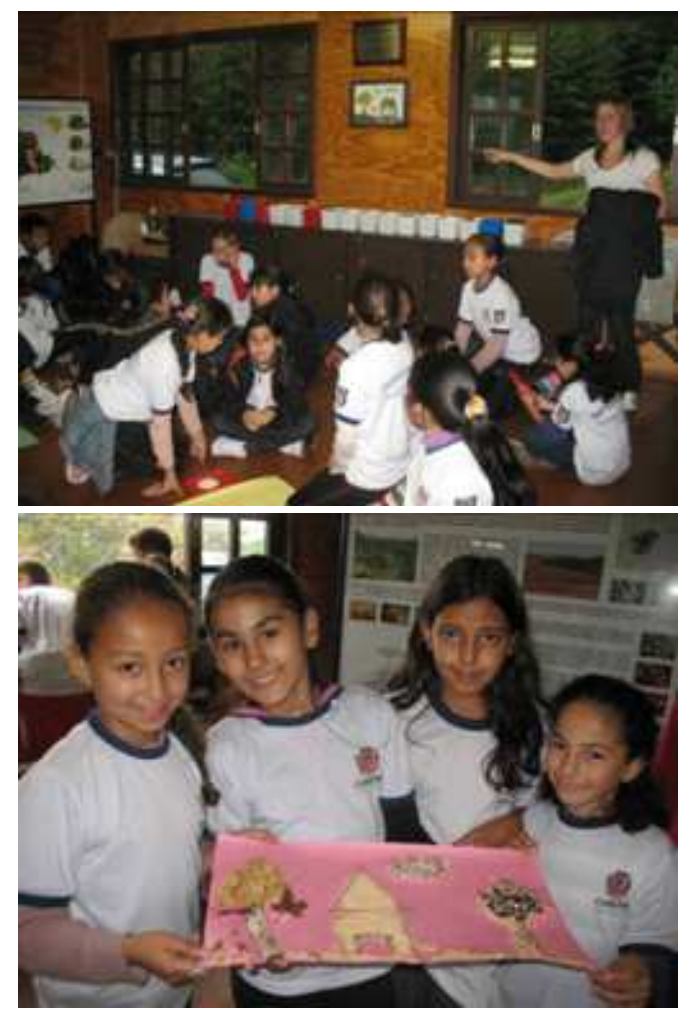

FIGURA 4 - OFICINAS DA FLORESTA

As atividades do projeto foram desenvolvidas por 19 acadêmicos do curso de engenharia florestal (4 bolsistas e 15 voluntários) e 1 de biologia (Figura 5). Para estes acadêmicos, este projeto foi uma grande oportunidade de praticar a extensão através da educação ambiental com crianças, experiência ímpar no seu curso. Tanto o contato com as crianças quanto a participação permanente em todas as fases do projeto, proporcionaram aos acadêmicos maior responsabilidade, autoconfiança, criatividade, expansividade, experiência e espírito de equipe.

O projeto apresentou ganhos sociais significativos porque conseguiu, através da educação ambiental, complementar as atividades práticas do currículo dos estudantes do ensino fundamental das escolas públicas. Além de atender as necessidades curriculares das escolas visitantes, também preenche a lacuna relativa às práticas de educação ambiental inexistentes no currículo atual do curso de Engenharia Florestal. Com isto os acadêmicos têm oportunidade de exercer conscientemente a práxis de extensão com as diferentes áreas de conhecimento deste curso através da educação ambiental.
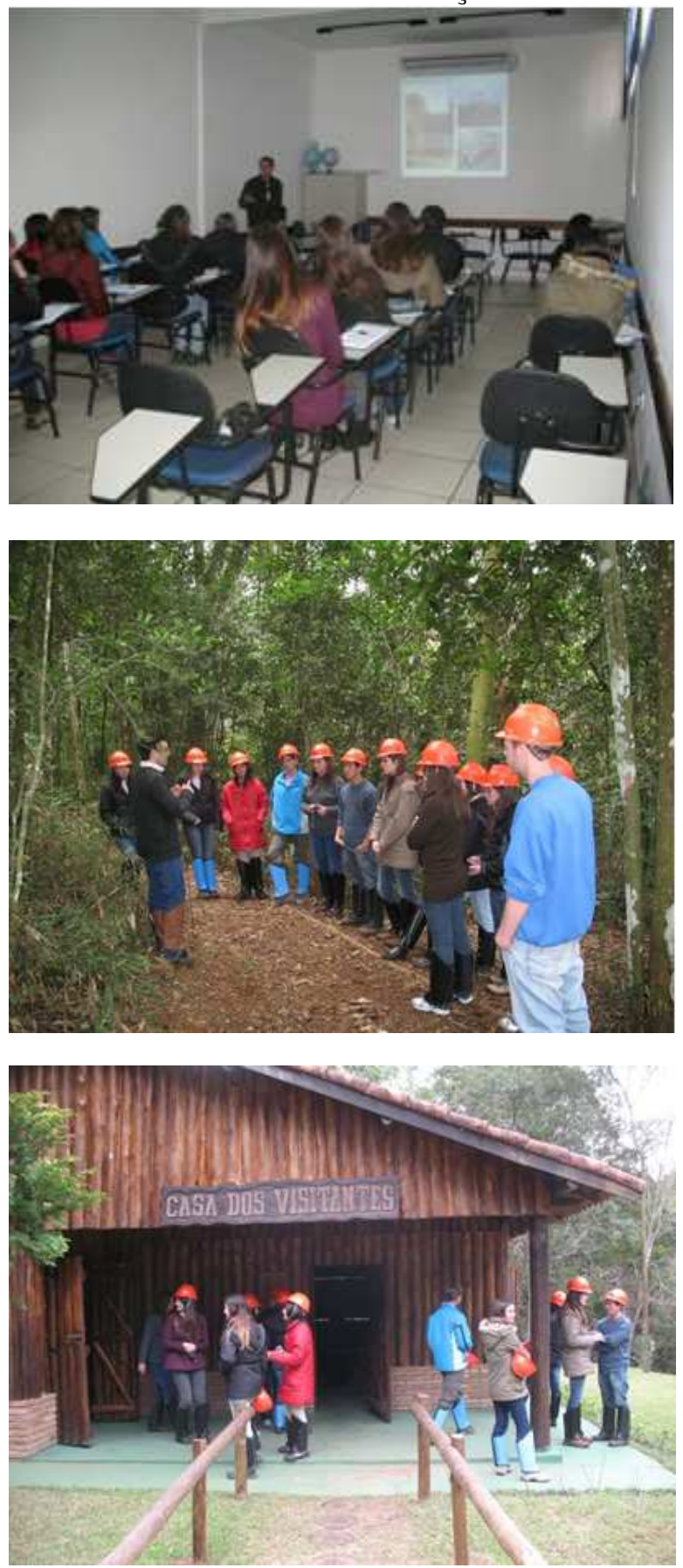

FIGURA 5. TREINAMENTO DOS BOLSISTAS DO PROJETO FLORESTA-ESCOLA

Em todas as ações do projeto o acadêmico logo percebe que não pode dissociar a trilogia "ensino/pesquisa/extensão". Da mesma forma, os acadêmicos não veem os

Extensão em Foco, Curitiba, n. 6, p. 37-46, jul./dez. 2010. Editora UFPR 
temas $e$ assuntos abordados nas atividades educativas com as crianças, como disciplinas ou matérias isoladas. Tanto na estrutura intelectual (conhecimentos) como na estrutura operacional do projeto é fácil observar que tanto os assuntos abordados e as pessoas envolvidas (academia e sociedade) fazem parte de um sistema, onde todos os componentes são vitais, sem hierarquia de importância. Isto faz com que eles sintam claramente o processo de interdisciplinaridade.

\section{Considerações finais}

A procura das escolas para a visitação da trilha é boa, mas é, na maioria das vezes, prejudicada pela falta de transporte $e$ pelas condições climáticas adversas, ocorrência de chuva.

O projeto proporcionou aos acadêmicos ganhos significativos no âmbito profissional e pessoal, tais como:

- Sentir que é um dever prestar algum serviço para a sociedade, enquanto aluno de universidade pública;

- Adquirir o hábito de pesquisar e estudar antes de elaborar ou executar alguma atividade;

- Ouvir as críticas visando melhorias do projeto;

- Sentir que, embora seja pequena sua contribuição, está fazendo alguma coisa pela natureza;

- Ter a experiência do sucesso (quando dá tudo certo) e a do fracasso (quando não foi como planejado);

- Transformar os conhecimentos técnico-científicos para uma linguagem coloquial;

- Ter a oportunidade de lidar e conviver com crianças;
- Sentir-se responsável pelos conhecimentos e a disciplina de um grupo de pessoas, mesmo que seja por duas horas.

Durante o ano 2010 o projeto "Floresta-Escola" articulou as seguintes ações com a comunidade interna: reunião semanal com os acadêmicos para reformular as ações (dialógica); treinamento dos acadêmicos na forma de expressar os conhecimentos técnico-científicos para as crianças (ensino/ extensão); treinamento dos acadêmicos em atividades lúdicas (dinâmicas) para as crianças (extensão); pesquisa com espécies de plantas e animais da floresta para transmitir essas informações durante a trilha (pesquisa).

Com a comunidade externa, foram articuladas as seguintes ações: divulgação, contato e agendamento das escolas para a trilha; contatos com escolas para a realização de palestras; busca de apoio logístico (transporte - viatura) da Secretaria Municipal de Defesa social para locomoção dos acadêmicos para as escolas (proferir palestras); visita a uma trilha elaborada pela empresa CONPACEL SP, parte de uma oficina desenvolvida pelo projeto (Figura 5).

Percebe-se que além das alterações feitas nas atividades desenvolvidas, que são analisadas e discutidas durante as reuniões semanais, o projeto parece estar sempre se renovando. Isto se deve à grande quantidade de discentes voluntários envolvidos e a alta rotatividade dos mesmos durante o ano.

\section{REFERÊNCIAS}

ARAUJO, I. A. A educação ambiental não formal no contexto das organizações não governamentais ambientalistas do litoral norte do estado de São Paulo. Dissertação (Mestrado em Educação) - Programa de Pós- Graduação 
BIONDI, D.; BATISTA, A. C. Projeto "Floresta-Escola" - educação ambiental não formal com instituições públicas

em Educação da UNIMEP, Universidade Metodista de Piracicaba, São Paulo, 2006.

BIONDI, D. Arborização aplicada à Educação ambiental. Curitiba: D. Biondi Ed. independente, 2008. 120 p.

DIAS, G. F. Educação Ambiental - princípios e práticas. 5 ed. São Paulo: Gaia, 2004. 551p.

GOHN, M. G. Educação não formal, participação da sociedade civil e estruturas colegiadas nas escolas. Ensaio: aval. pol. públ. Educ., Rio de Janeiro, v. 14, n. 50, p. 2738, jan./mar. 2006.

MACIEL, J. L.; WACHHOLZ, C. B.; ALMINHANA, C. O.; BITAR, P. G.; MUHLE, R. P. Metodologias de uma educação ambiental inclusiva. REVISTA EGP. Disponível em: $<$ http://www2.portoalegre.rs.gov.br/sma/revista_EGP/Metodologia_Jaqueline_outros.pdf.> Acesso em: 23/4/2011.

Texto recebido em 20 de maio de 2011.

Texto aprovado em 30 de junho de 2011. 